\title{
LA JURISPRUDENCIA CONTENCIOSO-ADMINISTRATIVA DE LAS ELECCIONES MUNICIPALES GENERALES DE 10 DE JUNIO DE 1987
}

\author{
POR \\ Antonio Martínez Martín
}

\begin{abstract}
SUMARIO: 1. PRECISIONES INTRODUCTORIAS.-2. ESTADÍSTICA JURISPRUDENCIAL.-3. AsPectos SUbJetivos. -4 . El objeto de los ReCURSOS.-5. Principales Fundamentos De DeReCho de los fallos SentenCiales. PRincipios electorales JURISPRUDENCIADOS: 5.1 La defensa del derecho electoral pasivo. Articulo 23 de la Constitución: a) Interpretación retrictiva de las inelegibilidades e incompatibilidades, b) El deber de la Administración electoral de defender el derecho de sufragio pasivo. c) La responsabilidad de las Juntas Electorales de sus propios errores.-5.2 $\mathrm{La}$ preservación de la elección: a) Irregularidades no determinantes del resultado de la elección. b) Irregularidades invalidantes de la elección. c) Irregularidades determinantes de la nulidad del voto.-5.3 La prevalencia de la voluntad de la organización electoral sobre la de los candidatos. -5.4 Los decimales de los cocientes determinan, en su caso, la adjudicación de los cargos concejiles entre las candidaturas.-6. CONSIDERACIONES FINALES.
\end{abstract}

\section{PRECISIONES INTRODUCTORIAS}

El derecho de sufragio es el fundamento de nuestro derecho público. La elección legitima el origen de nuestros gobernantes y determina en buena medida el ejercicio posterior del poder. La defensa judicial más importante y necesaria de la representatividad democrática es la contencioso-electoral. No obstante, este recurso es tan nuevo en nuestra historia legislativa local que sólo a partir de la Ley de Elecciones Locales de 17 de julio de 1978 puede hablarse en propiedad de su nacimiento. Los artículos 119 y 120 de la Ley de Jurisdicción Contencioso-Administrativa carecen, en razón del régimen dictatorial e insuficiencia reguladora, de la categoria suficiente para arrogarse la paternidad de esta institución de control electoral por antonomasia. Es otra obra más de nuestros constituyentes perfeccionada en la Ley Orgánica del Régimen Electoral de 1985.

La estructura procedimental descansa, con acierto en nuestra opinión, en una sola instancia procesal, salvo el supuesto del recurso de amparo electoral. No obstante, la composición judicial mayoritaria de las Juntas Electorales de zona sustenta la afirmación de que en la práctica son dos las instancias neutrales dirimitorias de los conflictos de las elecciones municipales. La ruptura institucional de los Ayuntamientos y Diputaciones Provinciales, si las Leyes eran progresistas, y de los alcaldes y gobernadores civiles, cuando los textos eran 
moderados, como administración electoral, o más tarde la composición corporativista de ésta es, sobre todo, una garantía de neutralidad y de buen quehacer. En este sentido, la presencia en la Junta Electoral de dos miembros propuestos por los partidos políticos es un retroceso sobre la íntegra naturaleza judicial de esta administración electoral de zona del Real Decreto-ley de 18 de marzo de 1977.

Este escrito se propone como finalidad ofrecer una información sobre la práctica contencioso-electoral de las elecciones municipales generales de 10 de junio de 1987. Son excluidas; por consiguiente, tanto las parciales celebradas unos meses más tarde como las de las entidades locales menores y las de las Diputaciones Provinciales. La inexistencia de publicación jurisprudencial completa de las sentencias de las Audiencias Territoriales y, desde luego, de éstas de índole electoral empuja aún más esta indagación, pues este control judicial de única instancia resulta decisivo en el ejercicio del derecho electoral. $\mathrm{El}$ objeto de esta referencia jurisprudencial son las mismas sentencias electorales de las Salas de lo Contencioso-Administrativo de España, pero no debe olvidarse las limitaciones cuantitativas que condicionan el alcance mismo de los datos, pues se carece de los textos decisionales de la mitad de las salas e, incluso, no se puede afirmar con rigor poseer la información completa -sólo la presumimos- de todos los recursos interpuestos ante las Audiencias de las que se han estudiado sus sentencias.

\section{ESTADISTICA JURISPRUDENCIAL}

El número de sentencias sobre el que se ha realizado este artículo es de 51. Diez Salas de lo Contencioso-Administrativo de España han correspondido a nuestro escrito peticionario y han remitido copia de los recursos contencioso-electorales sustanciados por ellas: Albacete, siete; Barcelona, Sala Primera, cuatro; Bilbao, cuatro; Burgos, seis; Granada, siete; Madrid, Sala Tercera, nueve; Murcia, cuatro; Oviedo, seis; Valencia, Sala Segunda, tres, y Zaragoza, una.

La Ley Orgánica del Régimen Electoral General contempla y regula dos recursos contencioso-electorales; el primero de ellos tiene como objeto los acuerdos de proclamación de las candidaturas por las Juntas Electorales y el segundo los acuerdos de las Juntas Electorales sobre proclamación de electos, así como la elección y proclamación de los presidentes de las Corporaciones locales. El número de recursos de proclamación de candidaturas ha sido 13, mientras que el de los elegidos ha casi triplicado la cifra de 38 casos. Las Salas sustanciadoras del primero han sido la de Albacete con dos, Bilbao con dos, Burgos con cuatro y Madrid con cinco. 
Si el número de recursos contencioso-electorales difiere de modo considerable entre los referidos a problemas de candidaturas y aquellos otros de concejales y alcaldes elegidos, los fallos de las sentencias ofrecen porcentajes opuestos en cuanto a su estimación o desestimación de los recursos. De los 13 primeros, nueve son estimados y cuatro desestimados; mientras que de los 38 segundos, sólo ocho son estimados y 30 desestimados.

\section{ASPECTOS SUBJETIVOS}

El recurso contra la proclamación de candidaturas por las Juntas Electorales puede interponerlo cualquier candidato excluido y los representantes de las candidaturas proclamadas o cuya proclamación hubiese sido denegada. De los 13 recursos estudiados, 10 de ellos han sido interpuestos por representantes de organizaciones electorales (partidos, federaciones y agrupaciones) y sólo tres de ellos por candidatos con candidatura no proclamada. Aun en el ámbito municipal, la defensa de la organización de sus candidaturas y candidatos es considerablemente superior a la individual -o colectiva- de los candidatos excluidos. En general son las organizaciones electorales quienes recurren contra la no proclamación de sus respectivas candidaturas; no obstante, en un supuesto (sentencia número 142, de 18 de mayo de 1987 de la Audiencia de Albacete), dos partidos con candidaturas proclamadas recurren la proclamación de una lista incompleta de otro partido $y$, en otro caso, un mismo objeto -no publicación injustificada de una candidatura- es recurrido tanto por la propia interesada como por la respectiva organización electoral (sentencias núms. 250 y 251, ambas de 17 de mayo de 1987, de la Sala Tercera de la Audiencia de Madrid).

La legitimación para interponer recurso contencioso-electoral contra los acuerdos de las Juntas Electorales sobre proclamación de concejales electos y contra los de la respectiva Corporación municipal sobre la elección y proclamación de los alcaldes la tienen atribuida: a) los candidatos proclamados o no proclamados; $b$ ) los representantes de las candidaturas concurrentes en la circunscripción, y c) los partidos políticos, asociaciones, federaciones y coaliciones que hayan presentado candidaturas en la circunscripción.

De los 38 recursos ćontencioso-electorales estudiados, 14 han sido interpuestos por la Federación de Partidos de Alianza Popular, seis por el Partido Socialista Obrero Español, cinco por el Centro Democrático y Social, cuatro por Coalición Electoral de Izquierda Unida, dos por Convergencia i Unió, una por la Agrupación de Electores Vecinos del Parets del Vallés, una por la Candidatura 
Independiente de Pechina, una por la Candidatura Independiente de San Juan de Gredos, una por la Unión del Pueblo de Molina, una por la Federación Socialista Asturiana y tres por concejales electos. Debe señalarse que dos de los recursos referidos han sido interpuestos conjuntamente por la Federación de Partidos de Alianza Popular y el Partido Socialista Obrero Español y por este último y Coalición Electoral de Izquierda Unida. Además, generalmente, son los representantes de las organizaciones electorales quienes interponen la mayoría de los recursos en representación de éstas.

Aun desconociendo el número total de candidaturas presentadas en las elecciones municipales por cada organización electoral, los recurrentes son de modo mayoritario, directa o a través de representante, las federaciones, coaliciones, partidos, candidaturas, uniones y agrupaciones electorales. Sin embargo, también los candidatos, ya colectiva, ya individualmente, han recurrido tanto la proclamación de candidaturas como la proclamación de concejales y elección o proclamación de alcaldes. Destaca de modo especial en el número de recursos interpuestos la Federación de Partidos de Alianza Popular. Asimismo, el carácter de los recurrentes manifiesta de modo inequívoco cómo la organización casi ha sustituido judicialmente al individuo y cómo son los partidos políticos mayoritarios en las Cortes quienes también en el escenario municipal representan los principales papeles.

\section{EL OBJETO DE LOS RECURSOS}

Los 13 recursos sobre proclamación o exclusión de candidatos o candidaturas como objeto del recurso contencioso-electoral, contemplado en el artículo 49 de la Ley Orgánica Electoral, se ha concretado en las siguientes causas: nueve recursos han sido interpuestos para recurrir la no proclamación de las respectivas candidaturas de lista, ya porque formalmente estaban incompletas -alguno de sus candidatos carecía de los requisitos legales o había renunciado individualmente ante la propia Junta-, porque habian sido sustituidas por otras por el propio partido, porque se habian presentado ante Junta Electoral de zona incompetente, presentada por representante incompetente, por falta de autenticación de las firmas o por presentarla extemporáneamente. Tres recursos tienen como causa la exclusión individual e injustificada de un candidato y uno la proclamación incompleta de una lista.

Los recursos interpuestos contra los acuerdos de proclamación de concejales prevista en el artículo 109, así como de la elección y proclamación de alcaldes, han sido 38 , de los cuales 34 impugnan 
algún extremo o a la misma elección concejil y consiguiente proclamación y cuatro recurren la elección y proclamación del alcalde. Las causas concretas determinantes de la impugnación han sido de modo prelativo las siguientes: error material en el cómputo de los votos electorales (7); invalidez o nulidad de los sobres o papeletas electorales, ya por no ajustarse al modelo oficial o por irregularidades invalidantes, como poner cruces o equis en las mismas papeletas de voto (7); falta de requisitos en el elector para el ejercicio del derecho de sufragio, como ser residente no censado, menor de edad y emitir el voto en dos municipios (5); irregularidades en las papeletas y sobres de los votos emitidos por correo (4); aplicación de decimales en los cocientes para la adjudicación de puestos concejiles (3); petición de que la elección sea anulada (3); discrepancia entre el número de votos y el de votantes (1); irregularidad de papeletas (1); no remisión de los votos nulos a la Junta Electoral (1); incompatibilidad de un concejal proclamado (1), y anomalía en el funcionamiento de una mesa electoral que abrió a las doce treinta horas del día 10 de junio (1). Los extremos concretos de los cuatro recursos impugnatorios de la elección y proclamación de los alcaldes han sido: inelegibilidad del concejal elegido alcalde (1), manifestación pública del voto para la elección del alcalde (1), elección del alcalde efectuada con anterioridad a la de la promesa o juramento del cargo concejil (1) e impugnación general de la proclamación y elección del alcalde (1).

\section{PRINCIPALES FUNDAMENTOS DE DERECHO DETERMI- NANTES DE LOS FALLOS SENTENCIADOS. PRINCIPIOS ELEC- TORALES JURISPRUDENCIADOS}

\subsection{La defensa del derecho electoral pasivo. Artículo 23 DE LA CONSTITUCIÓN}

\section{a) Interpretación restrictiva de las inelegibilidades e incompatibi- lidades.}

La Audiencia de Albacete (sentencias núms. 202 y 214 , de 10 y 17 de julio de 1987), ante el problema planteado de incompatibilidad del cargo concejal/alcalde con el desempeño del puesto de jefe local de sanidad en base al artículo 178.2, b), de la Ley Orgánica del Régimen Electoral General de 19 de junio de 1985 -son incompatibles con la condición de concejal los directores de servicios, funcionarios o restante personal activo del respectivo Ayuntamiento y de las entidades y establecimientos dependientes de él- desestima ambos recursos. El dato fáctico que excluye la aplicación del mencionado precepto no es otro que la dependencia de la Jefatura Local de Sanidad de la 
Comunidad Autónoma de Castilla-La Mancha y, por consiguiente, no se encuentra literalmente incompatibilizada. Además, y así es mencionado de modo expreso por ambas sentencias: «el precepto debe interpretarse de modo restrictivo, no ampliando su letra a extremos no contenidos en su espíritu». La incompatibilidad legal se establece con la finalidad de separar el interés particular de un funcionario municipal y el general del municipio, al que como concejal o alcalde debe defender. Dada la dependencia funcionarial de la Jefatura Local del Servicio de Sanidad de la Comunidad Autónoma, este supuesto no se encuentra incompatibilizado según la letra del precepto mencionado y la interpretación extensiva sería improcedente, pues es la restrictiva la que debe aplicarse para salvaguardar el derecho a participar en los asuntos públicos constitucionalizado en el artículo 23.

b) El deber de la Administración electoral de defender el derecho de sufragio pasivo.

La jurisprudencia considera que las Juntas Electorales deben desempeñar una función activa en el ejercicio del derecho electoral. En este sentido, ante una lista de un partido político que ha sido proclamada con siete candidatos titulares y tres suplentes en vez de nueve y tres, respectivamente, el recurso interpuesto por otros dos partidos con candidaturas proclamadas en la circunscripción contra dicha proclamación de candidatura de lista incompleta ha sido estimado parcialmente, pero lo ha sido en el sentido de exigir la responsabilidad a la propia Junta Electoral de Zona por no haber comunicado al partido de la lista la mencionada irregularidad y la necesidad de que fuese completada para ser proclamada. La Audiencia de Albacete (sentencia núm. 142, de 18 de mayo de 1987) ha condicionado el acuerdo de proclamación de la mencionada candidatura al trámite de subsanación, concediéndole a ésta el plazo legal de las cuarenta y ocho horas para poder completar la lista.

La jurisprudencia ha responsabilizado también a las Juntas Electorales de notificar a las respectivas organizaciones electorales cualquier circunstancia ajena que haya determinado la no proclamación de su candidatura y cuyo conocimiento no sea exigible según las exigencias de la diligencia debida a la respectiva organización electoral. Las Audiencias de Bilbao (sentencia núm. 179, de 16 de mayo de 1987) y de Madrid (sentencia núm. 248, de 15 de mayo de 1987) estiman los recursos de las respectivas organizaciones electorales contra la falta de proclamación de sus respectivas candidaturas de lista por estar incompletas. Alegan como causa la renuncia individual ante el respectivo órgano electoral de un candidato y el desconocimiento que sobre tal extremo poseían. Las respectivas salas estiman los recursos, 
declaran el deber de las Juntas Electorales de comunicar esta irregularidad y conceden un plazo de subsanación de cuarenta y ocho horas para que los respectivos partidos completen sus listas.

c) La responsabilidad de las Juntas Electorales de sus propios errores.

La jurisprudencia responsabiliza a las Juntas Electorales de sus propios errores o de la falta de diligencia debida en el desempeño de su función protectora y eficaz del derecho de sufragio pasivo electoral. Las manifestaciones concretas de disfuncionalidad de las Juntas juzgadas son las siguientes: la Audiencia de Madrid, Sala Tercera, estima un recurso interpuesto de una candidatura aceptada y no publicada por una Junta Electoral de zona incompetente y posibilita la extemporaneidad ante la Junta competente, pues aquélla es la causante de este retraso con la aceptación indebida de la candidatura (sentencia núm. 149, de 17 de mayo de 1987). La misma Sala estima los recursos interpuestos por una candidata y el respectivo partido por el error de no proclamar la candidata número $7 \mathrm{de} \mathrm{la} \mathrm{lista} \mathrm{(sentencias}$ números 250 y 251 , de 17 de mayo de 1987).

Igualmente son estimados los recursos impugnatorios de los acuerdos erróneos o indebidos de las Juntas Electorales referidos a errores materiales en el cómputo de votos y las consiguientes desproclamaciones/proclamaciones de concejales (sentencias de los recursos contencioso-electorales 753 y 779 , de 8 y 15 de julio de 1987, Audiencia de Oviedo). Incluso, la Audiencia de Burgos (sentencia de 16 de julio de 1987) declara válidos los votos anulados de una lista que contenía cuatro suplentes por haber sido un error en la confección de la lista por el Gobierno Civil y remitidas a los residentes fuera del municipio que habian solicitado el voto por correo a la oficina del Censo Electoral, delegación de Burgos. En el mismo sentido se pronuncia la Audiencia de Granada (sentencia núm. 474, de 13 de julio de 1987) al desestimar el recurso petitorio de declaración de nulidad de la proclamación de concejales de una candidatura por no ajustarse las papeletas al modelo oficial y presentar equivocado el segundo apellido del tercer suplente. La Audiencia desestima el recurso en base a que tales papeletas habían sido verificadas por la Junta Electoral de zona competente.

\subsection{LA PRESERVACIÓN DE LA ELECCIÓN}

a) Irregularidades no determinadas del resultado de la elección.

El artículo 113.3 de la Ley Orgánica del Régimen Electoral General dispone que «No procederá la nulidad cuando el vicio del procediREVISTA DE ESTUDIOS.-3 
miento electoral no sea determinante del resultado de la elección. La invalidez de la votación en una o varias secciones tampoco comporta la nulidad de la elección cuando no se altere el resultado final». La jurisprudencia considera de modo unánime que el resultado de la votación se refiere a la adjudicación de puestos de concejales, y mientras que esta distribución no resulte alterada no debe anularse la elección. El fragmento jurídico mencionado ha sido, al menos en ocho sentencias, el fundamento jurídico determinante de la desestimación del recurso.

La Audiencia de Barcelona, Sala Primera (sentencia núm. 381, de 29 de julio de 1987), considera que aun incumpliendo lo establecido en el artículo 97 -los votos nulos deben adjuntarse al acta- y presumiendo que el voto nulo fuera favorable al recurrente, el resultado de la elección no se alteraría. La Audiencia de Granada (sentencia núm. 473, de 13 de julio de 1987), aun admitiendo las irregularidades de determinados votos emitidos por correo, mantiene la validez de la elección en cuanto que aun con el número de éstos se mantendria la atribución de los puestos de concejales. Con el mismo fundamento jurídico del artículo 113 de la Ley Orgánica desestima un recurso impugnatorio de la elección basado en la emisión del sufragio de dos menores de edad (sentencia núm. 478, de 13 de julio de 1987). En el mismo sentido desestimatorio y manteniendo la validez de la elección, por no verse alterado el resultado, se pronuncia la Audiencia de Oviedo (recurso núm. 790, de 13 de julio de 1987) ante un error material en el cómputo de los votos; la de Valencia, Sala Segunda (sentencia núm. 276, de 16 de julio de 1987), ante el hecho comprobado de un elector que ha emitido el voto en dos municipios; la de Albacete, sede en Murcia (sentencia núm. 226, de 9 de julio de 1987), ante las irregularidades en el cómputo de votos de una Mesa Electoral.

La Audiencia de Madrid, Sala Tercera (sentencia núm. 358, de 14 de julio de 1987), no anula la elección ante el hecho demostrado de que la lista proclamada mayoritaria en votos por la Junta Electoral era realmente la segunda. Mantiene la validez de la elección en cuanto el error numérico no alteraba la adjudicación de puestos concejiles; sin embargo, estimando parcialmente el recurso, proclama como ganadora a la lista de la candidatura recurrente a efectos de la formación de los órganos representativos del municipio -cuando ningún candidato obtiene la mayoría concejil será alcalde el cabeza de la lista más votada-. Al amparo del mismo artículo 113.3 , se desestima un recurso impugnatorio de la proclamación de concejales, pues el recurrente considera que el procedimiento electoral habia sido infringido: el presidente de una única Mesa Electoral de un municipio de candidaturas abiertas, ante la avalancha de personas en el acto del escrutinio 
y para impedir el extravio de papeletas ya leídas, aunque no computadas, introduce éstas de nuevo en la urna, aunque sin soltarlas de la mano. Dada la coincidencia de papeletas y votantes, la circunstancia señalada y no demostrarse la manipulación de votos, la Audiencia de Albacete (sentencia núm. 206, de 14 de julio de 1987) considera que el mencionado fragmento electoral no se ha visto conculcado.

b) Irregularidades invalidantes de la elección.

La jurisprudencia estudiada ofrece dos sentencias con pronunciamiento sobre irregularidades invalidantes de la elección. El fundamento jurídico determinante del fallo anulatorio no es otro que la incidencia alteratoria del resultado que la irregularidad pudo producir. La Audiencia de Albacete (sentencia núm. 213, de 17 de julio de 1987) anula la elección ante el hecho de la emisión del voto de una electora no inscrita en el censo electoral, el empate de cuatro candidatos y el empleo de la fórmula de sorteo para la elección de uno de ellos, dado el sistema de lista abierta del pequeño municipio de 164 electores. En la medida que el voto pudo incidir en el resultado de la elección y no ser, consiguientemente aplicable el artículo 113 de la Ley Electoral, la Sala anula la elección y declara la necesidad de efectuar nueva convocatoria. La misma Audiencia (sentencia núm. 215, de 17 de julio de 1987) estima un recurso impugnatorio de la proclamación de concejales por la Junta Electoral: el quebrantamiento de los requisitos procedimentados para la emisión del voto por correo 97 sobres no certificados en las urnas infringiendo expresamente el articulo $73.2 \mathrm{de}$ la Ley Electoral- y el número suficiente de éstos para desequilibrar el resultado electoral producido determinan, ante el desamparo del artículo 113, la anulación de la elección y la necesidad de nueva convocatoria.

\section{c) Irregularidades determinantes de la nulidad del voto.}

La adopción por nuestro legislador del sistema de candidaturas de listas completas, cerradas y bloqueadas ha determinado la escrupulosidad extrema del artículo 96.2: «Serán nulos también los votos emitidos en papeletas en las que se hubiera modificado, añadido, señalado o tachado nombres de los candidatos comprendidos en ella o alterado su orden de colocación, así como aquéllas en las que se hubiera producido cualquier otro tipo de alteración». En base a este precepto anulatorio de, en la práctica, cualquier manifestación preferencial del elector, la jurisprudencia ha desestimado dos recursos tendentes a dar validez a papeletas anuladas por las Juntas Electorales que tenían escritas equis o cruces junto al nombre de algunos de los 
candidatos. La aplicación literal, y desde luego también espiritual, del precepto prohibitivo de cualquier manifestación individual en las papeletas sobre las candidaturas propuestas por las organizaciones electorales se ha jurisprudenciado de modo expreso (Audiencia de Oviedo, recursos 746 y 791 , de 8 y 15 de julio de 1987).

\subsection{La PREVAlENCIA DE LA VOLUNTAD DE LA ORganización ELECTORAL SOBRE LA DE LOS CANDIDATOS}

El reinado de las organizaciones como el signo de nuestra época preside omnipoderosamente nuestra Ley electoral. Son éstas quienes presentan, modifican $\mathrm{y}$, en su caso, retiran las candidaturas. El artículo 44 reconoce esta legitimación a los partidos, federaciones, coaliciones y agrupaciones de electores y son sus representantes o promotores quienes realizan esta tarea ante las Juntas Electorales. Ciertamente, la jurisprudencia se ha mostrado generosa aceptando que el representante de la organización electoral pueda ser - dada la indeterminación del mencionado artículo 44- tanto el representante de la candidatura como el del partido (Audiencia de Burgos, núm. 461 , de 16 de julio de 1876). Sin embargo, la jurisprudencia expresamente ha sentenciado que los candidatos, aunque fueran todos los miembros de la lista, no deciden en absoluto sobre la candidatura, y de ahí que sea el representante o promotor, en cuanto expresa la voluntad de la organización electoral, quien decide única y válidamente ante la Junta Electoral la modificación o sustitución de la candidatura respectiva. Incluso si el representante es sustituido por otro, éste puede presentar nueva candidatura en cuanto expresa la voluntad del partido (Audiencia de Burgos, sentencia núm. 460, de 16 de mayo de 1987. Audiencia de Bilbao, sentencia núm. 753, de 16 de mayo de 1987).

\subsection{Los DECIMALES DE LOS COCIENTES DETERMINAN, EN SU CASO, LA ADJUDICACIÓN DE LOS CARGOS CONCEJILES ENTRE LAS CANDIDATURAS}

El artículo 163 de la Ley Electoral dispone que los escaños se atribuyen a las candidaturas que obtengan cocientes mayores, y en el supuesto de empate entre varias de ellas, el escaño se atribuye a la que mayor número de votos hubiese obtenido. La jurisprudencia ha interpretado que en los cocientes no sólo deben tenerse en cuenta los enteros, sino también los decimales. La expresión del cociente incluye tanto los enteros como los decimales y sólo en el supuesto de mantenerse el empate con ambas cifras procede adjudicar el puesto concejil a la lista que mayor total de votos hubiese obtenido 
(Audiencia de Barcelona, Sala Primera, sentencia núm. 816, de 15 de julio de 1987. Audiencia de Oviedo, sentencia núm. 766, de 10 de julio de 1987. Audiencia de Valencia, Sala Segunda, sentencia núm. 277, de 16 de julio de 1987).

\section{CONSIDERACIONES FINALES}

La novedad de la puesta en práctica de los recursos contenciosoelectorales en las elecciones municipales, las peculiares caracteristicas de este proceso, la importancia cronológica para la elección o nueva convocatoria electoral y la trascendencia que como control del ejercicio del derecho electoral tiene motivan estas últimas precisiones.

Los recursos estudiados, aun siendo un número bastante incompleto con relación al número total, posibilita afirmar la operatividad y bondad de este control judicial de las elecciones municipales. La jurisprudencia de estos comicios demuestra que ambos recursos han sido practicados y que tanto los supuestos subjetivos legitimados para interponerlo como los múltiples extremos objetivados han actuado y servido para encontrar la justicia electoral necesaria.

El número de recursos y su distribución entre las Salas de las Audiencias ha posibilitado responder a las características de este proceso sumario, no necesitado de postulación y pretendidamente gratuito. En efecto, algunos de ellos han sido interpuestos por el representante de la organización electoral sin abogado y procurador alguno. La gratuidad ha sido en la práctica una característica general de las sentencias estudiadas, pues a excepción de tres de ellas -Burgos, 14 de julio de 1987; Murcia, 13 de julio de 1987, y Oviedo, 15 de julio de 1987-, no se ha impuesto condena en costas por considerar que las posiciones mantenidas no eran infundadas.

La improrrogabilidad y la consideración natural de los días de los plazos señalados, así como su carácter urgente y preferencial, han ayudado a una sustanciación práctica ajustada a la letra de la Ley. La cronología de las sentencias es sorprendentemente laudatoria: a excepción de una de 25 de mayo de 1987, el resto lleva fecha de los días $15,16,17$ y 18 del mes citado. En cuanto a las propias del recurso de elección y proclamación de concejales y alcaldes, se pronuncian todas durante el mes de julio de 1987 y muy mayoritariamente en los días 13, 14, 15, 16 y 17 de este mismo mes. Las primeras fechas normalizan la continuidad del proceso electoral para la votación del 10 de junio de 1987 y las segundas, en la medida que anulan algunos comicios en el mismo mes de julio, posibilitan que por Real Decreto de 11 de septiembre de 1987 se convoquen elecciones parciales para el domingo 8 de noviembre del mismo año. 
Formalmente, las sentencias tienen en general una extensión breve, pues la mayoria de ellas suele contenerse en 4,5 ó 6 páginas de folio mecanografiado a doble espacio. Las Audiencias de Granada y Oviedo ofrecen las sentencias de mayor extensión y la Sala Tercera de la de Madrid las de menor, pues a excepción de una que tiene cuatro páginas, las demás no pasan de tres e incluso una se recoge en sólo dos. El estilo suele ser claro y el vocabulario puede ser considerado como no especializado y de fácil comprensión para la generalidad. Sólo las sentencias de la Sala Segunda de los Contencioso de la Audiencia de Madrid traslucen una premura en su razonamiento jurídico y adolecen comparativamente de claridad en la exposición de los hechos y rigor que las demás, en general, ofrecen. La vertebración unánime de todas las decisiones estudiadas se asienta en los antecedentes de hecho, fundamentos juridicos y el fallo; aunque la Audiencia de Zaragoza excepcionaliza su decisión con los resultandos, los considerandos y el fallo.

De las sentencias estudiadas sólo una ha sido recurrida en amparo ante el Tribunal Constitucional, que, negándolo, ha mantenido el fallo de la Audiencia de Burgos. No obstante, el número de recursos de amparo electoral determinado por estas elecciones municipales ha sido, en rigor, 13; de los que cuatro se han estimado y nueve desestimado.

Evidenciada la operatividad de estos recursos, este informe no puede menos de ver en la mayoritaria composición judicial de las Juntas Electorales de zona, en el nivel cultural del país, en la exigencia de la organización electoral para presentar candidaturas y, en último término, aunque no el menos importante, en la calidad técnica de la misma Ley factores determinantes de este logro. 